\title{
MAPA DA VEGETAÇÃO NATIVA DECLARADA NO CADASTRO AMBIENTAL RURAL - CAR EM MONTES CLAROS-MG
}

\author{
MAP OF NATIVE VEGETATION DECLARED IN THE RURAL ENVIRONMENTAL \\ REGISTER - CAR IN MONTES CLAROS-MG
}

\section{MAPA DE VEGETACIÓN NATIVA DECLARADA EN EL REGISTRO AMBIENTAL RURAL - CAR EN MONTES CLAROS-MG}

\author{
Wagner Aparecido Silva Aparecido ${ }^{1}$ https://orcid.org/0000-0003-4673-8716
}

\begin{abstract}
RESUMO
Objetivou-se explanar o mapa com o quantitativo declarado de vegetação nativa ao Cadastro Ambiental Rural - CAR, em Montes Claros-MG, no período de 2012 a 2019. Norteado na teoria geossistêmica, utilizou-se: o número disponibilizado pelo IEF/SICAR referente à vegetação declarada em hectares, inserção deste ao Sistema de Informação Geográfica -SIG ArcGIS onde foram tabulados, e, somados às convenções cartográficas, resultaram na elaboração do mapa. Do total de 8.070 imóveis cadastrados, 4.439 deles declararam a vegetação nativa a qual encontra-se: predominante no entorno do Parque Estadual da Lapa Grande, onde foi declarada vegetação de cerca de 2.907 a 7.773 hectares, nas médias propriedades que cadastraram cerca de 300 a 2.906 hectares e nas pequenas propriedades que cadastraram porções de 01 a 160 hectares de vegetação. O mapa ainda apresenta cor branca referente à vegetação não castrada, bem como pontos escuros referentes às áreas de solo exposto. Preservar a vegetação de Cerrado e a Floresta Estacional Decidual montesclarenses motivou mapear, para melhor monitoramento e o CAR mostrou-se eficaz instrumento de regularização ambiental neste quesito.
\end{abstract}

Palavras-chave: Mapa. Vegetação. Territorializações. Regularização. Monitoramento.

\begin{abstract}
The objective was to explain the map with the declared quantity of native vegetation to the Rural Environmental Registry - CAR, in Montes Claros-MG, in the period from 2012 to 2019. Based on geosystemic theory, the following was used: the number provided by IEF / SICAR regarding vegetation declared in hectares, insertion of this into the Geographic Information System - GIS ArcGIS where they were tabulated, and, added to the cartographic conventions, resulted in the elaboration of the map. Of the total of 8,070 registered properties, 4,439 of them declared the native vegetation to be found: predominant around the Lapa Grande State Park, where vegetation of about 2,907 to 7,773 hectares was declared, in the medium properties that registered about 300 to 2,906 hectares and in small properties that registered portions of 01 to 160 hectares of vegetation. The map still has a white color referring to the non-castrated vegetation, as well as dark spots referring to the exposed soil areas. To preserve the

\footnotetext{
${ }^{1}$ Mestrando em Geografia - PPGEO-UNIMONTES. Bolsista FAPEMIG. E-mail: wagnersilvachaves@ hotmail.com
} 
Mapa da vegetação nativa declarada no Cadastro Ambiental Rural - CAR em Montes ClarosMG

Wagner Aparecido Silva

Cerrado vegetation and the Montesclarenses Seasonal Deciduous Forest motivated mapping, for better monitoring and the CAR proved to be an effective instrument for environmental regularization in this regard.

Keywords: Map. Vegetation. Territorialization. Regularization. Monitoring.

\section{RESUMEN}

El objetivo fue explicar el mapa con la cantidad de vegetación declarada al Registro Ambiental Rural CAR, en Montes Claros-MG en el período de 2012 a 2019. Con base en la teoría geosistémica, se utilizó lo siguiente: el número proporcionado por IEF / SICAR respecto a la vegetación declarada en hectáreas, inserción de ésta en el Sistema de Información Geográfica - GIS ArcGIS donde fueron tabulados, y sumado a las convenciones cartográficas, resultó en la elaboración del mapa. Del total de 8,070 propiedades registradas, 4,439 de ellas declararon la vegetación nativa que se encuentra: predominante alrededor del Parque Estatal Lapa Grande, donde se declaró vegetación de aproximadamente 2,907 a 7,773 hectáreas, en las propiedades medianas que registraron alrededor de 300 a 2,906 hectáreas y en pequeñas propiedades que registraron porciones de 01 a 160 hectáreas de vegetación. El mapa aún presenta color blanco referido a la vegetación no castrada, así como puntos oscuros referidos a las áreas de suelo expuestas. Para preservar la vegetación del Cerrado y el Bosque Estacional Caducifolio Montesclarenses motivó el mapeo, para un mejor monitoreo y la CAR resultó ser un instrumento eficaz para la regularización ambiental en este sentido.

Palabras clave: Mapa. Vegetación. Territorialización. Regularización. Seguimiento.

\section{INTRODUÇÃO}

A conservação da vegetação nativa é fundamental para a proteção da flora e da fauna que compõem os diversos biomas terrestres. Como as áreas cobertas por vegetação nativa têm a função ambiental: de serem a principal fonte de fornecimento de oxigênio (responsável pela evolução e subsistência do metabolismo aeróbico), de ampliar o potencial dos cursos d'água superficiais e aquíferos, da manutenção da paisagem natural, da estabilidade geológica, da conservação da biodiversidade, da proteção do solo e de assegurar o bem-estar da espécie humana, e, dada a importância de mapear e quantificar as partes e o todo de cobertura vegetal nativa que foi declarado no Cadastro Ambiental Rural - CAR no município de Montes Claros -MG, do ano de 2012 a 2019, justifica-se a escolha do tema deste artigo.

O programa Cadastro Ambiental Rural - CAR, criado pela Lei 12.651/12, no âmbito do Sistema Nacional de Informação sobre o Meio Ambiente (SINIMA) serviu de embasamento na contrução do mapa coroplético tema deste artigo. O CAR tem por objetivo constituir uma base de dados estratégica para o controle, o monitoramento e o combate ao desmatamento das florestas e demais formas de vegetação nativa brasileiros. Sendo o programa declaratório, surgiu neste artigo a necessidade de quantificar e mapear o total em hectares (ha) de vegetação 
Mapa da vegetação nativa declarada no Cadastro Ambiental Rural - CAR em Montes ClarosMG

Wagner Aparecido Silva

do município de Montes Claros -MG cadastrada nele e assim, pelos princípios geográficos da territorialidade e localização, disponibilizar a delimitação do quantitativo de vegetação cadastrada, bem como a localização através de cores, polígonos e manchas indicadores de onde ela se encontra.

Sabe-se que o CAR diferencia o sistema de regularização ambiental brasileiro daqueles adotados nos demais países. Segundo levantamento do Instituto Climate Policy Initiative, vinculado à PUC-Rio, o Brasil é a potência agrícola com legislação ambiental mais rigorosa. Segundo a referida pesquisa, nos Estados Unidos que são um dos mais importantes concorrentes do Brasil no comércio exterior no agronegócio, em vários estados sequer há obrigatoriedade de manutenção de Áreas de Preservação Permanentes - APPs- em áreas agrícolas. "O Brasil é o país que possui, de longe, as maiores faixas marginais de proteção de cursos d'água. A APP deve ser composta por vegetação nativa e os proprietários não recebem compensação financeira devido a esta limitação no uso da propriedade", aponta o estudo, o qual mostra ainda que todos os demais países analisados possuem programa de compensação (pagamento) pela manutenção de APPs. E, mesmo em países com legislações mais rigorosas, como a Alemanha, é permitida a exploração econômica das áreas preservadas, prática que é vetada por lei no Brasil. "Na Alemanha, a Lei Nacional de Recursos Hídricos estabelece a obrigação de manter faixas marginais de proteção de no mínimo cinco metros ao longo de cursos d'água, aplicável somente em áreas edificáveis. Entretanto, é permitida a prática de agricultura e o uso de fertilizantes nesta área, desde que sejam adotadas boas práticas agrícolas. Quando se compara a legislação florestal de diferentes países, conclui-se que as leis brasileiras possuem um grau de proteção de vegetação bastante alto, mas ainda há muito a ser feito no sentido de preservar a biodiversidade", disse Juliano Assunção, diretor executivo do CPI/ NAPC e professor do Departamento de Economia da PUC-Rio.

Esta necessidade de mapear e preservar a vegetação nativa declarada no CAR reforça-se, quando se lê o dado divulgado pela Fundação SOS Mata Atlântica, em 23 de maio de 2019, o qual mostra Minas Gerais a liderar, pela sexta vez, o ranking de estados que mais desmataram entre os anos de 2017 e 2018 e que os índices de vegetação no Norte de Minas foram drasticamente reduzidos nos últimos 150 anos, devido ao intenso processo de ocupação do interior mineiro, conduzido pela expansão da agricultura, pecuária e extração mineral. Somado a este fato, o censo agropecuário realizado pelo Instituto Brasileiro de Geografia e Estatística IBGE (2006), também divulgou o aumento da expansão das fronteiras agrícolas e mostra a região Sudeste registrando índices de 50,4\% de expansão e para tanto, houve perda de vegetação. Ainda há muito dever a cumprir, principalmente no que diz respeito ao 
Mapa da vegetação nativa declarada no Cadastro Ambiental Rural - CAR em Montes ClarosMG

Wagner Aparecido Silva

monitoramento e fiscalização. De acordo com Pougy et al., (2015, p. 28), a expansão das florestas plantadas, da pecuária e agricultura, sem o devido cuidado para a conservação dos recursos naturais, tem gerado fortes pressões sobre o ambiente natural, colocando alguns animais e plantas sob ameaça e o desaparecimento dos cursos de água e deixa em desvantagem a biodiversidade do norte de Minas Gerais. A proposta de construção do mapa coroplético tema deste artigo expõe áreas de solo exposto, bem como áreas de vegetação não cadastradas no CAR no município de Montes Claros -MG, exatamente onde a expansão da silvicultura e a expansão da formação de pastagens são intensas e isso urge aos órgãos ambientais e o município estarem atentos ao de que ainda dispõe de Cerrado e Floresta Estacional Decidual, a serem preservados.

O CAR apresenta-se como programa eficaz na preservação da cobertura vegetal nativa, porque por intermédio dele, todas as informações referentes à situação ambiental das Áreas de Preservação Permanente, das áreas de Reserva Legal, das florestas e dos remanescentes de vegetação nativa, das Áreas de Uso Restrito e das áreas consolidadas das propriedades e posses rurais do país (FIGURA 01) estão disponíveis a toda população. Surge como uma possibilidade de fomento para a formação de corredores ecológicos e para a conservação dos demais recursos naturais, o que contribui para a melhoria da qualidade ambiental.

Figura 01: Representação de um imóvel rural, com área de reserva florestal legal, APP e área de uso alternativo do solo .

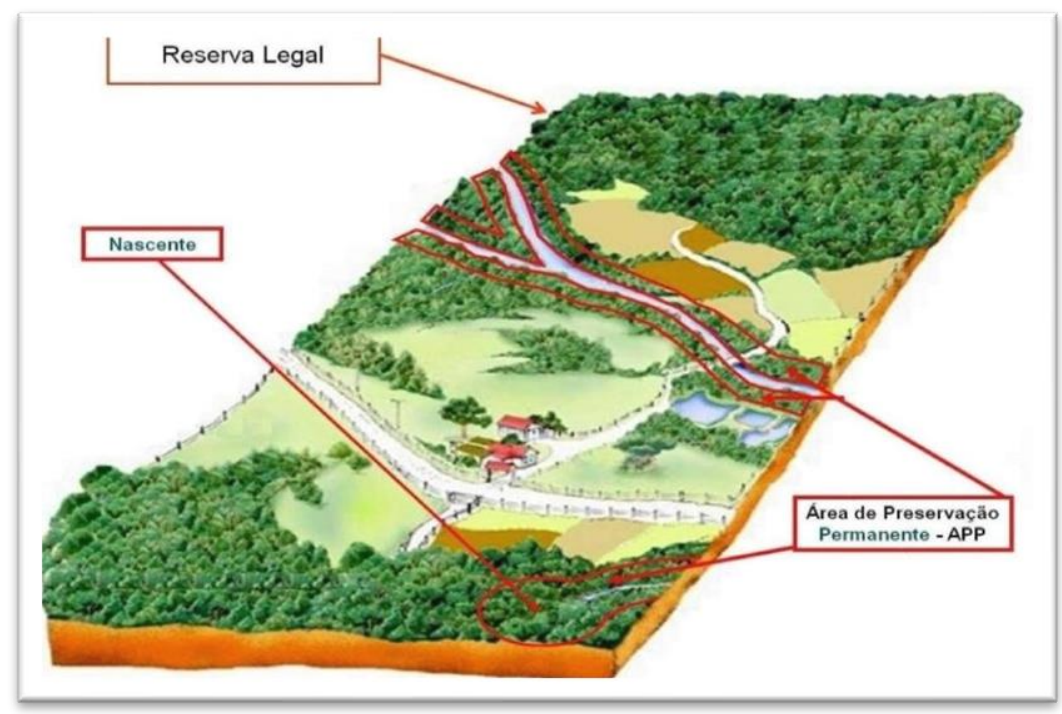

FONTE: IEF - MG, disponível: site: 〈<http://www.ief.mg.gov.br/cadastro-ambiental-rural-car $>$. Acesso em: 03 de abril de 2020.

A elaboração do mapa referente à vegetação nativa montesclarense declarada no CAR e demarcada em linha, ponto, polígono, obedecendo aos parâmetros prescritos no Novo Código 
Mapa da vegetação nativa declarada no Cadastro Ambiental Rural - CAR em Montes ClarosMG

Wagner Aparecido Silva

Florestal concretiza a territorialização e, assim, aquilo que defende Haesbaert (2004,p.95) que apresenta territorialidade como a ação do sujeito sobre a área delimitada motivado por ato de subjetividade, política e relação econômica, forneceu embasamento para a compreensão de que, no mapa da vegetação declarada no CAR em Montes Claros -MG este tripé se verifica, porque o sujeito demarca a sua propriedade, declara o quantitativo de vegetação nativa e o georreferencia, porque as políticas públicas ambientais assim o exigem e o mapa coroplético abrange dimensão política, já que territorializa a porção rural do espaço conforme as políticas ambientais brasileiras promulgam; econômicos porque da cobertura vegetal nativa declarada depende a subsistência e os modos de produção do homem habitante, e, subjetividade porque o imóvel rural com sua paisagem, delimitação, "seu lugar"- como diz o produtor rural montesclarense- são a sua identidade.

A territorialização proporcionada pelo mapa da vegetação montesclarense cadastrada no CAR, dos anos 2012 a 2019, buscou subsídio teórico na territorialidade que Andrade (1994, p. 19) descreve como processo subjetivo do homem sobre a área que delimitou como sua, antes de tudo, como área de gestão, seja gerida pelo Estado ou pelo sujeito que a demarcou como sua e averbou diante das instâncias do poder público. O norteamento teórico fornecido por esta visão de Andrade acerca da territorialização como ato de gerir é coerente com a razão de ser do CAR, visto que nesta proposta, a gestão da área territorializada atende aos interesses da defesa do meio ambiente no território demarcado, bem como área de interesse social gerida pelos órgãos ambientais competentes. No contexto do município de Montes Claros -MG, onde, antes da Lei 11.428 de 2006, conhecida popularmente como Lei da Mata Seca, houve grande perda da vegetação nativa do Cerrado e da Floresta Estacional Decidual (Mapa 01) e consequente perda de habitat das espécies da fauna características destas fitofisionomias faz-se necessário um programa de monitoramento como o CAR para gerir estas áreas. Para evidenciar a situação da cobertura vegetal nativa, hoje, em Montes Claros -MG é que o mapa abaixo (MAPA 01) e gráfico (GRÁFICO 01), elaborados em 2021, como parte das atividades da disciplina Sistemas de Informação Geográfica - SIG, no Programa de Pós-Graduação em Geografia na Universidade Estadual de Montes Claros, contextualizam o potencial de vegetação nativa e representa as áreas de uso antrópico: 
Mapa da vegetação nativa declarada no Cadastro Ambiental Rural - CAR em Montes ClarosMG

Wagner Aparecido Silva

Mapa 01: Fitofisionomias do município de Montes Claros-MG

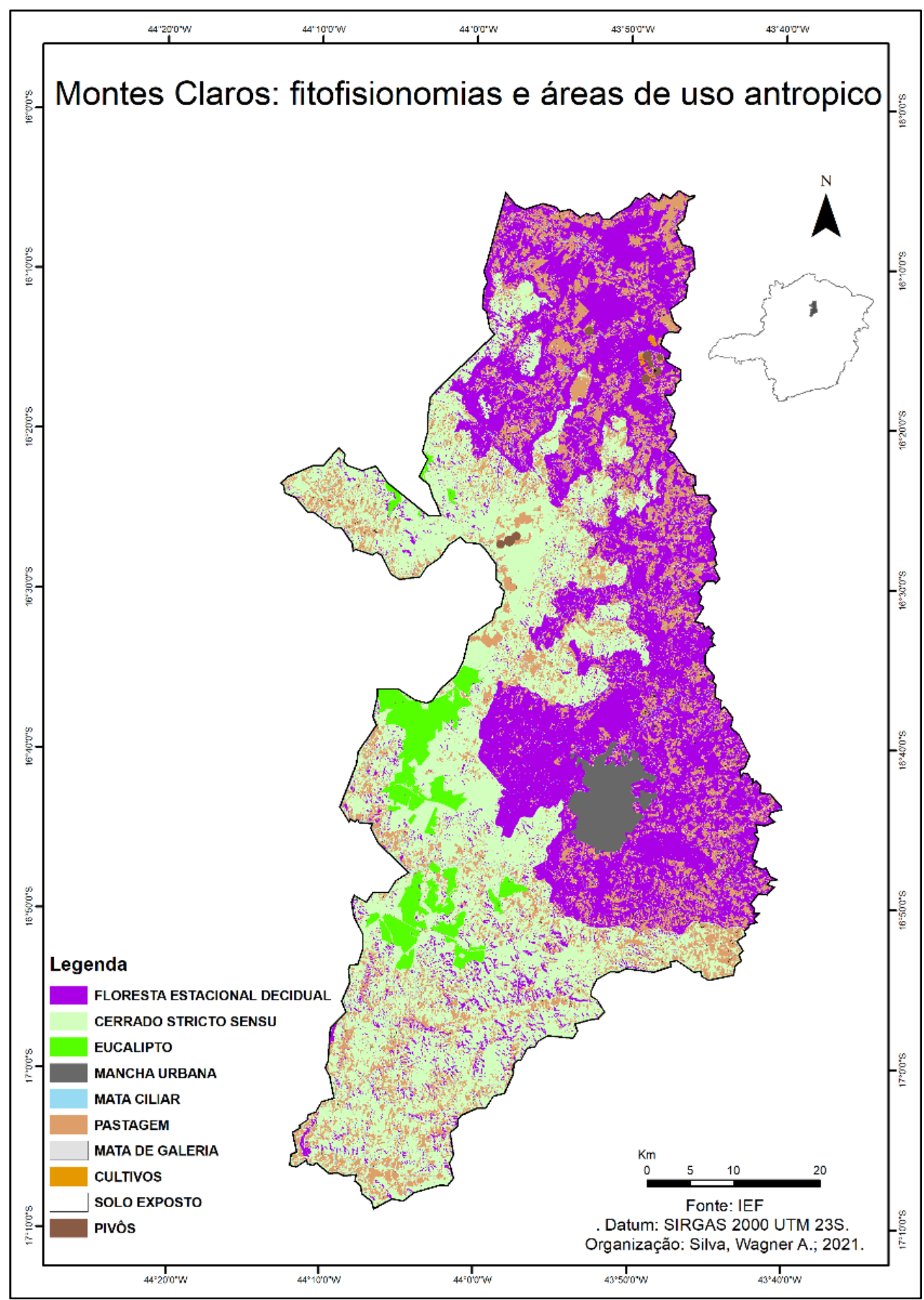

FONTE: Sensor OLI, Landsat 08, INPE, 2018. Organização: O Autor, 2021. 
Mapa da vegetação nativa declarada no Cadastro Ambiental Rural - CAR em Montes ClarosMG

Wagner Aparecido Silva

Gráfico 01: Percentual das áreas de uso antrópico do solo e áreas de cobertura natural de vegetação em Montes Claros- MG.

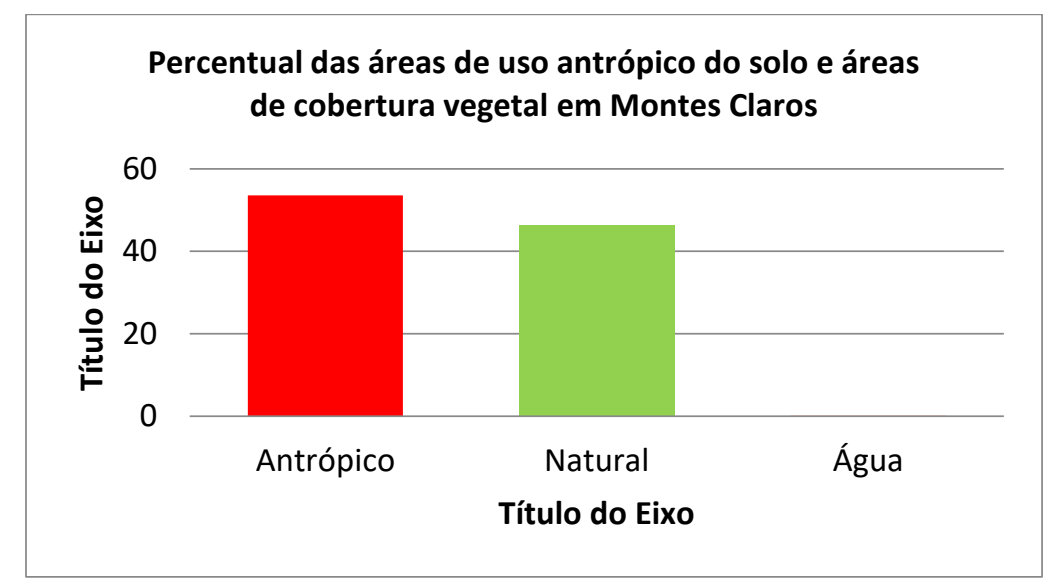

Organização: o Autor, 2020.

À luz da leitura do mapa (mapa 01), pode-se inferir que: o município dispõe de um potencial de Floresta Estacional Decidual e Cerrado Stricto Sensu consideráveis, mas houve intensificação das atividades antrópicas e retirada da cobertura vegetal nativa. Percebe-se que na porção ocidental, o Cerrado predomina, mas destacam-se intervenções antrópicas exemplificadas nas formações de pastagens e, a sudoeste, há significativo plantio de eucalipto. Já na área central, a mancha urbana intensifica com consequente aumento da área impermeabilizada, das ilhas de calor e retirada da vegetação. Na porção oriental do município, bem como nas áreas setentrionais, é possível detectar que as áreas de uso antrópico consolidado (pastagens, cultivos e pivôs) avançaram. Outro aspecto preocupante é que na porção sudeste do mapa, isto é, a região onde se localiza um grande curso d’água, o rio Verde Grande, de importância vital para a cidade e o município como um todo - a ação antrópica se destaca e o potencial de cobertura vegetal nativa estagnou. $\mathrm{O}$ mesmo predomina nesta mesma porção do mapa onde se localiza a barragem de Juramento que abastece hidricamente a cidade. Mas o aspecto animador do mapa da imagem de satélite é que a área de vegetação predominante na porção oeste da cidade de Montes Claros caracteriza a Unidade de Conservação denominada Parque Estadual da Lapa Grande, onde há extensa área de Florestas Estacionais Deciduais, Matas Ciliares e outras formações savânicas e florestais do bioma Cerrado preservados, mas que precisam do contínuo monitoramento do poder público e da população, no sentido de evitar desmates ilegais, uso irregular do solo, incêndios e assoreamento dos cursos d'água que atravessam a referida unidade de conservação. 
Mapa da vegetação nativa declarada no Cadastro Ambiental Rural - CAR em Montes ClarosMG

Wagner Aparecido Silva

Segundo os percentuais do gráfico (GRÁFICO 01), os cerca de 53\% de áreas de uso antrópico e de $48 \%$ de áreas de cobertura vegetal ratificam a gravidade da expansão de desmates. É possível ainda interpretar que, antes da promulgação da Lei 11.428, de 22 de dezembro de 2006, que incorporou a fitofisionomia Floresta Estacional Decidual ao bioma Mata Atlântica é que se intensificou esta destruição das áreas verdes, intervenções antrópicas estas diretamente ligadas à bovinocultura, formação de pastagens, construção civil, silvicultura e aumento da área impermeabilizada. Os dados do Sistema Integrado de Monitoria - SIM, do Instituto Estadual de Florestas - IEF/ Escritório Regional Norte (2015) permitiram detectar que muitos destes tipos de intervenção ambientais aconteceram sem o Documento Autorizativo de Intervenção Ambiental - DAIA e, no caso dos grandes empreendimentos, sem Licença Ambiental, ou seja, foram supressão de cobertura vegetal nativa sem autorização do órgão ambiental competente, o que agrava o problema e intensifica as áreas de desmates. Este mapa (Mapa 01) e gráfico (GRÁFICO 01) despertam para a importância do mapeamento e quantificação de cobertura vegetal nativa no CAR e a enxergar o CAR como ferramenta eficaz de regularização ambiental e monitoramento.

Por assim ser, objetivou-se aqui expor o mapa daquilo que foi cadastrado de vegetação no CAR referente aos imóveis rurais do município de Montes Claros -MG, para que uma vez mapeado e quantificado, redunde em conservação da biodiversidade das fitofisionomias montesclarenses, bem como em um maior monitoramento e fiscalização do potencial desta cobertura vegetal nativa declarada no CAR e inquirição acerca do quantitativo de vegetação não declarada, a fim de que o poder público encontre os caminhos para a inserção delas ao referido cadastro.

\section{MATERIAL E MÉTODOS}

\section{ÁREA DE ESTUDOS}

A região estudada é a zona rural do município de Montes Claros-MG, localizado à mesorregião do Norte do Estado de Minas Gerais, compreendido entre as latitudes $16^{\circ}$

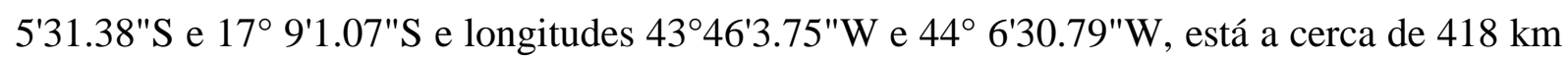
da capital mineira, Belo Horizonte. Possui clima tropical semiúmido, de acordo com a classificação climática de Köppen, temperatura média anual de $24^{\circ} \mathrm{C}$ e índice médio pluviométrico anual de $1.074 \mathrm{~mm}$, segundo o INMET (2017). Segundo o censo do IBGE (2010), o município de Montes Claros possuía uma população de 361.915 habitantes, composta de 17.488 pessoas residentes na zona rural e de 344.427 pessoas na zona urbana (o que corresponde a aproximadamente $95,17 \%$ da população total do município). Montes Claros é o 
Mapa da vegetação nativa declarada no Cadastro Ambiental Rural - CAR em Montes ClarosMG

Wagner Aparecido Silva

sexto mais populoso município do estado de Minas Gerais e o $62^{\circ}$ mais populoso do Brasil. Em 2019, a população do município de Montes Claros foi estimada, pelo IBGE, em 409.341 habitantes.

De acordo com Scolfloro, J. R.; Carvalho, L. M. T., (2006, p. 39), no norte de Minas Gerais, enfaticamente no município de Montes Claros, predominam as seguintes formas de vegetação: o Cerrado St e Floresta Estacional Decidual (MAPA 01). As espécies vegetais nativas do Cerrado que se destacam em Montes Claros-MG são: pitombeira (Talisia esculenta), pequizeiro (Caryocar brasiliense), coquinho-azedo (Butia capitata), mangaba (Hancornia speciosa), jabuticaba (Myrciaria cauliflora Berg), panã (Anonna crassiflora), jatobá (Hymenaea courbaril L.), coco-macaúba (Acrocomia aculeata), jenipapeiro (Genipa americana L.), araçá (Psidium firmun), pau terra (Qualea parviflora), jacarandá (jacarandá mimosifolia), aroeira do cerrado (Myracrodruon urundeuva Allemão), tingui (Magonia pubescens), araticum (Anonna montana), buritizeiro( Mauritia flexuosa) e ipê (Handroanthus). As principais espécies vegetais nativas da Floresta Estacional Decidual montesclarense são: barriguda (Cavanillesia umbellata), aroeira do sertão (Urundueva), pau d'arco (Tabebuia), angico (Anadenanthera colubrina), umburana (Comiphora leptopholeos), mandacaru (Cereus jamacaru) e umbuzeiro (Spodias tuberosa). A importância do Cadastro Ambiental Rural - CAR para a preservação destas espécies reside no fato de que, no processo do cadastro, os produtores rurais montesclarenses declararam estas espécies nativas das quais algumas são imunes de corte, como o pequizeiro. Declaradas, elas são inseridas no potencial de vegetação do imóvel rural, quer da área dos $20 \%$ da reserva florestal legal, quer da área de APP ou nas áreas da vegetação remanescente.

\section{PROCEDIMENTOS}

Para a elaboração do mapa coroplético referente à vegetação nativa cadastrada no CAR, no período de 2012 a 2019, foi utilizada a metodologia proposta por Slocum et al., (2009, p.47) cujo princípio baseia-se na teoria geossistêmica exemplificada nos mapas coropléticos. Quanto à teoria geossistêmica que norteia este artigo, ela é parte integrante do arcabouço teórico e metodológico da Geografia Física. Mas as primeiras explicitações da Geografia como ciência ideologicamente orientada, os debates deterministas e possibilistas da segunda metade do século XIX e os representantes da escola naturalista são a fonte de inspiração da abordagem geossistêmica. Esta teoria norteia este mapeamento das fitofisionomias montesclarenses no CAR, visto que só a abordagem geossistêmica vem de encontro para fornecer, não só subsídio 
Mapa da vegetação nativa declarada no Cadastro Ambiental Rural - CAR em Montes ClarosMG

Wagner Aparecido Silva

teórico e metodológico, mas também fomentar a conscientização ambiental e abrir caminhos para as proposições analíticas chamarem à atenção das políticas públicas para o monitoramento e defesa destas áreas de proteção ambiental. Formulada pela escola russa por meio de Viktor Borisovitch Sochava, mas difundida na Europa Ocidental, nos EUA e no Brasil pelo empenho do geógrafo George Bertrand, no Brasil, os periódicos do Instituto de Geografia da USP é que publicaram textos de Bertrand e Sochava no Caderno da Terra e nos cadernos Biogeografia e Métodos em Questão. Sotchava (1977, p.51) expõe que a teoria geossistêmica resulta da combinação local e única de elementos da paisagem enquanto sistema dinâmico, hierarquizado e interligado na relação homem-sociedade/natureza. Já Bertrand (1972, p. 27) explicita que a abordagem geossistêmica é taxonômica, pois suas escalas, bem como o eixo temporalmetodológico articulam: as interfaces, geofaces e geótopos e a taxonomia podológica, fitológica, climática, geológica, geomorfológica e biogeográfica. Hoje, a teoria geossistêmica é predominante no âmbito das burocracias das empresas de reflorestamento, reposição florestal, consultoria ambiental, geoprocessamento e sensoriamento remoto.

Sobre os mapas coropléticos, segundo Slocum et al. (2009, p.47), "coroplético" tem sua etimologia no grego "choros" que significa "área, lugar e região" e "phlethos" que significa "mapa". O mapa coroplético representa o espaço geográfico por meio de áreas simbolizadas com cores, sombreamentos ou padrões, de acordo com uma escala que representa a proporcionalidade da variável estatística. Mesmo que um mapa coroplético não disponha de todas as convenções respectivas dos demais tipos de mapas, mas eles atendem às demandas de localização e quantificação de fenômenos verificados nas categorias paisagem, território, lugar, região e espaço, e, no caso do total em hectares de vegetação declarada no CAR pelos produtores rurais do município de Montes Claros - MG, o mapa coroplético reproduz em forma de cores, pontos e polígonos onde estão as áreas de vegetação cadastrada, as áreas não cadastradas, as predominantes e aquelas com menor número de cobertura vegetal nativa cadastradas. Tais mapas são formas de elementos da cartografia social, visto que não se prendem aos padrões pragmáticos da cartografia tradicional e são formas das comunidades representarem o espaço em que vivem, atuam e como o concebem político, econômica, social e culturalmente. Implica em não delimitar o espaço tão somente pelos objetos geográficos, mas pelos conhecimentos associados a seu uso, onde se incorpora o conhecimento dos diferentes interesses, levando à legitimidade. Configura-se como um instrumento que possibilita mapear as delimitações do território e defender seus interesses, assegurando seus direitos e atendendo seus anseios. Busca preservar o patrimônio socioeconômico e cultural das comunidades e 
Mapa da vegetação nativa declarada no Cadastro Ambiental Rural - CAR em Montes ClarosMG

Wagner Aparecido Silva

também buscar melhoramentos estruturais que possibilite uma melhora na qualidade de vida daquele grupo (ACELRAD, 2010, p.12).

A coleta dos dados para a elaboração do mapa foi realizada entre março a novembro de 2020. Para obtenção destes, contou-se com o fornecimento do quantitativo de áreas cadastradas pelos técnicos do Instituto Estadual de Florestas - IEF, Escritório Regional Norte de Montes Claros -MG. Estes, através do sistema SICAR disponibilizaram o total em hectares de vegetação cadastrada, o quantitativo de imóveis cadastrados e suas respectivas áreas de reservas florestais legais, área de preservação permanente - APPs, áreas de uso consolidado do solo e de vegetação remanescente. Os dados fornecidos pelo IEF não informam a fitofisionomia da vegetação cadastrada, mas informam que é referente à vegetação nativa do imóvel, excetuando, é claro: a área dos $20 \%$ da reserva florestal legal, das respectivas áreas de APP. O mapa não pôde ir além daquilo que a coleta dos dados permitiu, porque a pandemia da covid 19 é um entrave às visitas às propriedades cadastradas para obter informações mais exatas e precisas sobre a vegetação as quais não constam neste artigo, mas futuramente podem ser complementadas, após a pandemia. Da obtenção dos dados e dada a dificuldade ocasionada pela pandemia, recorreu-se às novas tecnologias disponíveis no âmbito cartográfico.

Em seu livro Geoprocessamento sem Complicação, Fitz (2008) dedicou-se ao estudo de como as novas tecnologias no estudo do espaço geográfico tornaram-se importantes desde a segunda metade do século XX. Ele dedica três capítulos da referida obra para falar sobre a importância dos softwares, como o sistema ARCGIS na facilitação do controle, monitoramento, fotos, georreferenciamentos e dados rasters, vetoriais, linhas, pontos e polígonos referentes ao mapeamento de determinadas áreas do espaço geográfico. A olhar por este prisma das novas tecnologias, o CAR, assim como o ARCGIS, apresentam-se como instrumentos facilitadores da fiscalização ambiental e até mesmo da gestão das propriedades nele inseridas, visto que muitos cadastros em cartório não estabelecem tanta segurança jurídica quanto um sistema que vai disponibilizar para o público todas as informações de um determinado imóvel rural. O expresidente do Instituto Nacional de Colonização e Reforma Agrária -INCRA, Francisco Graziano, em 2012, se posicionou a favor do CAR, alegando ser uma das vantagens da nova lei florestal para facilitar a fiscalização ambiental, pois o monitoramento de áreas rurais por sensoriamento remoto é, sem dúvida, uma ferramenta importante para a gestão ambiental. O ARCGIS mostra-se como programa eficiente na produção de elementos representadores do espaço geográfico, sobretudo durante a pandemia da covid 19 que impede a vistoria técnica in loco no espaço objeto de estudo e no contato direto com os sujeitos centralidades da pesquisa, 
Mapa da vegetação nativa declarada no Cadastro Ambiental Rural - CAR em Montes ClarosMG

Wagner Aparecido Silva

porque não lança mão do sensoriamento remoto e geoprocessamento, mas é um Sistema de Informação Geográfica - SIG- facilitador na arte de construir mapas.

O processo de elaboração do mapa coroplético concretizou-se no sistema ARCGIS, versão 10.8, obedecendo às seguintes ações: inserção da base de dados do CAR no diretório/pasta de trabalho no disco C/: do computador; utilização de projeção UTM, datum SIRGAS 2000, lançamento dos dados da referida pasta no ARCGIS; seleção da quantidade total de áreas/ hectares (ha) dos imóveis cadastrados disponíveis na planilha excel na qual o IEF armazenou; seleção das cores do mapa: preto para as áreas que representam solo exposto na zona rural, no perímetro urbano de Montes Claros-MG, bem como dos distritos. As lacunas em branco para representar a vegetação presente no mapa, mas não declarada e não cadastrada no CAR. Cor verde escura para os polígonos que representam imóveis que declararam e cadastraram de 01 a 69,47 hectares de cobertura vegetal nativa , cor verde clara para a cobertura vegetal nativa declarada entre 69,48 a 300,02 hectares, cor amarela para as áreas de 300,03 a 936,98 hectares, cor alaranjada para os polígonos que representam 936,99 a 2.906,34 hectares de vegetação cadastrados e cor vermelha para as áreas que totalizaram 2.906,35 a 7.772,95 hectares de cobertura vegetal nativa cadastrados. Selecionadas as cores, foram inseridas as coordenadas geográficas, projeção UTM, Datum SIRGAS 2000 e, por fim, as convenções cartográficas. O IEF, através do sistema SICAR forneceu os números e as planilhas de excel os quais lançados no ARCGIS, em forma de polígonos, receberam as cores acima citadas e selecionadas com base no total em hectares de vegetação declarada, segundo o sistema SICAR. O polígono colorido representa a cobertura vegetal declarada, excetuando: a vegetação dos $20 \%$ da reserva legal e a das áreas de preservação permanentes -APPs. As lacunas em branco representam as áreas de vegetação não declarada e os minúsculos pontos escuros representam as áreas de solo exposto. Para representar o imóvel, sua respectiva vegetação declarada utilizou-se o método que os técnicos do IEF usam no sistema AutoCAD e na vistoria técnica: o mapa coroplético, linhas, manchas, coordenadas UTM, polígonos e cores para representarem porções do espaço geográfico, territorializá-las para melhor as gerir e monitorar.

Para a elaboração no sistema ARCGIS do mapa das fitofisionomias e áreas de uso antrópico em Montes Claros -MG a partir da imagem de satélite (Mapa 01), contou-se com dados do sensoriamento remoto para criar o mapa e gráfico (gráfico 01) que contemplem as áreas de cobertura vegetal nativa e as áreas de uso consolidado do solo e seus respectivos percentuais. Para isso foi utilizada imagem do Landsat 8, do sensor OLI com resolução espacial de $15 \mathrm{~m}$ por $15 \mathrm{~m}$ registradas no ano de 2018 e disponibilizadas pelo INPE (Instituto Nacional de pesquisas), com coordenadas UTM, Zona 23S, DATUM SIRGAS 2000, Brazil, longitude 
Mapa da vegetação nativa declarada no Cadastro Ambiental Rural - CAR em Montes ClarosMG

Wagner Aparecido Silva

$44^{\circ}, 00^{\prime} \mathrm{W}$, latitude $16^{\circ} 30^{\prime} \mathrm{S}$. A representação da área de cobertura vegetal nativa levou em conta três classes, sendo elas: Naturais: Cerrado, Floresta Estacional Decidual, mata ciliar e vegetação remanescente. E as áreas de uso antrópico: eucalipto, pivô central, pastagem, mancha urbana, solo exposto e mineração. Foram representados igualmente os pontos de ocorrências do potencial hídrico do município. É válido ressaltar que para a identificação dos objetos de cada classificação foram utilizadas as variáveis visuais como cor e forma, além de conhecimento prévio da espacialização do município. Disposta a imagem de satélite do município, procedeu-se a seleção das cores das três bandas básicas das imagens de satélite: Blue (Banda 1: azul, a que se atribuiu a simbologia 1 no Arcmap), Green (Banda 2: verde, a que se atribuiu a simbologia 3) e Red (Banda 3: vermelho, a que se atribuiu a simbologia 5). Selecionadas as cores, foi então efetuada a coleta das amostras no sistema Arcmap, utilizandose um polígono para as desenhar e as coletar, referentes às dez classes acima citadas. Coletadas as amostras, procedeu-se a classificação supervisionada, a junção das classes coletadas cada uma em suas respectivas categorias (antrópico, natural e água) e assim construído o mapa. A relevância do mapa oriundo da imagem de satélite foi para fins de comparação com o quantitativo de vegetação declarada e cadastrada no CAR, no período de 2012 a 2019, tema deste artigo, e reforçar a necessidade de preservar o potencial de fitofisionomias do bioma Cerrado e Floresta Estacional Decidual que o mapa resultante da imagem de satélite (Mapa 01) representa.

\section{RESULTADO E DISCUSSÃO}

O mapa refere-se à vegetação nativa declarada pelos produtores rurais no CAR, no período de 2012 a 2019, no município de Montes Claros -MG. O total de imóveis cadastrados é de 8.070 (oito mil e setenta) cujas áreas somam e totalizam: 258.529,59 hectares, segundo o SICAR. Destes 8.070 imóveis, quatro mil e quatrocentos e trinta e nove (4.439) declararam a vegetação nativa no CAR e o mapeamento, (Mapa 02), objetivando territorializar para melhor preservação e monitoramento é referente às áreas destes 4.439 imóveis, a saber: 
Mapa da vegetação nativa declarada no Cadastro Ambiental Rural - CAR em Montes ClarosMG

Wagner Aparecido Silva

Mapa 02: Vegetação nativa cadastrada no Cadastro Ambiental Rural - CAR, em Montes Claros MG, no período de 2012 a 2019

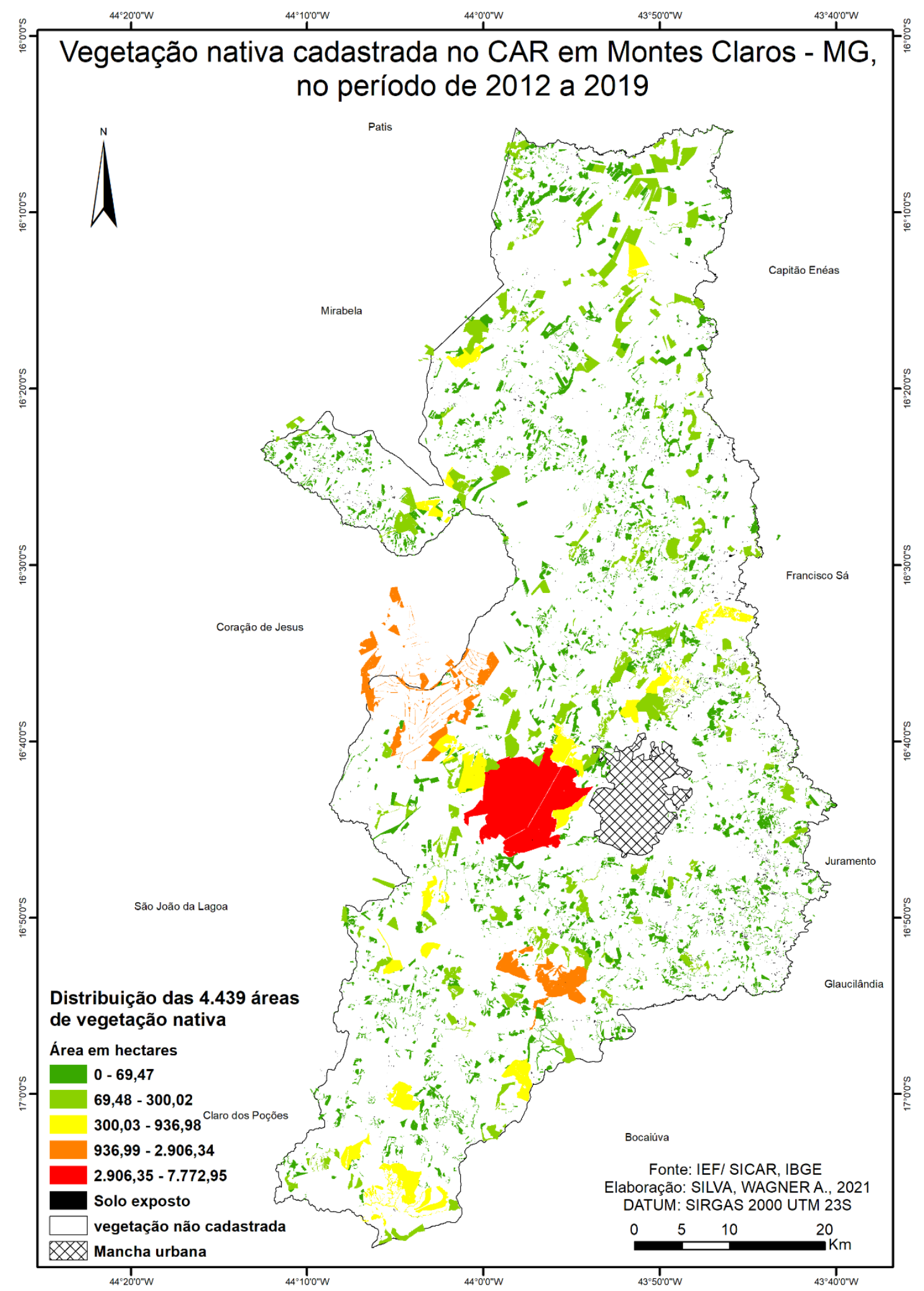

FONTE: IEF/ SICAR, 2020. ORGANIZAÇÃO: O autor, 2020. 
Mapa da vegetação nativa declarada no Cadastro Ambiental Rural - CAR em Montes ClarosMG

Wagner Aparecido Silva

01- As áreas representadas no mapa coroplético pelos pontinhos pretos representam as ocorrências de solo exposto. Ao Norte, destacam-se nas propriedades localizadas próximas: aos distritos de Aparecida do Mundo Novo e São Pedro da Garça. Na porção centro-sudeste do mapa, a grande área de mosaico de cores pretas refere-se ao perímetro urbano, isto é, a cidade de Montes Claros -MG. Ao centro-sul, as áreas de solo exposto verificam-se no distrito de Canto do Engenho, na ponta oeste é a área do distrito de Ermidinha e nas áreas centrais os distritos de Miralta e Nova Esperança.

02- As áreas em cores brancas referem-se à vegetação existente, mas não cadastrada no CAR. Destacam-se ao extremo leste montesclarense, onde há predomínio de floresta plantada (eucalipto), na borda situada a sudeste que é referente às áreas de preservação permanente próximas à barragem de Juramento e nos topos de morro e terras altas que divisam Montes Claros -MG e Juramento, bem como Montes Claros, Guaraciama e Bocaiúva - MG. Aparecem no extremo sudeste do mapa, onde está localizado o maior trecho de mata ciliar do alto rio Verde Grande, importantíssimo curso d'água para o município de Montes Claros -MG

03- Os polígonos de cor verde escura representam a vegetação cadastrada em áreas com total de 01 a 69,47 hectares. Destacam-se na região centro-sul de Montes Claros e em alguns pontos do norte e nordeste, evidenciando que o cadastro de poucas porções de vegetação aconteceram nos imóveis rurais nas proximidades do distrito de Aparecida do Mundo Novo, São Pedro das Graças, Santa Rosa de Lima, Vila Nova de Minas e ao centro sul perto da cidade de Montes Claros -MG e do distrito de Canto do Engenho.

04- As áreas em verde claro no mapa coroplético representam a vegetação declarada em porções de 70 a 300 hectares. O mapa possibilita visualizar este percentual significativo de vegetação sobretudo na porção central do município de Montes Claros, nos imóveis localizados entre a cidade de Montes Claros, o distrito de Miralta e Nova Esperança. A norte, estes quantitativos de vegetação cadastrada no CAR também são destaques.

05- Os polígonos em amarelo e alaranjado apresentam vastos hectares de vegetação nativa cadastrados no CAR: amarelos se referindo às porções de vegetação com 300 a 936 hectares de cobertura vegetal nativa declarada e os polígonos alaranjados: 937 a 2.906 hectares e são propriedades com quantidade considerável de vegetação declarada 
Mapa da vegetação nativa declarada no Cadastro Ambiental Rural - CAR em Montes ClarosMG

Wagner Aparecido Silva

localizadas ao sul de Montes Claros -MG, nas proximidades com o distrito de Canto do Engenho, na porção sudeste, norte e noroeste do Parque Estadual da Lapa Grande a oeste da cidade de Montes Claros -MG.

06- A grande área vermelha, que segundo o quantitativo disponibilizado pelo IEF se referem a um total de 2.907 a 7.773 hectares de vegetação declarada no CAR é o destaque do mapa coroplético. Representa a vegetação das propriedades localizadas no entorno ou dentro da unidade de conservação - Parque Estadual da Lapa Grande, a oeste da cidade de Montes Claros -MG.

Acerca dos pontozinhos quase invisíveis no mapa, em cores pretas, isto é, às áreas de solo exposto, o Norte, destacam-se nas propriedades localizadas próximas: aos distritos de Aparecida do Mundo Novo e São Pedro da Garça. Segundo o IEF (2015), as maiores intensidades de solo exposto no município de Montes Claros-MG devem-se à retirada de cobertura vegetal nativa antes da promulgação da Lei 11.428 de 2006, para fins de bovinocultura e agricultura e formação de pastagens. As formas rudimentares de agricultura e as queimadas ocasionaram a perda do solo e intensificaram as áreas de solo exposto. Na porção centro-sudeste do mapa, o mosaico entrelaçado de cores pretas refere-se ao perímetro urbano, isto é, a cidade de Montes Claros -MG. Ao centro-sul, as áreas de solo exposto verificam-se no distrito de Canto do Engenho, na ponta oeste é a área do distrito de Ermidinha e nas áreas centrais os distritos de Miralta e Nova Esperança. A ação antrópica para a organização espacial dos distritos envolveu supressão de cobertura vegetal nativa e, consequentemente, aumento da área impermeabilizada e perda de vegetação de Cerrado e Mata Seca predominantes no norte e nordeste do município de Montes Claros-MG. A efetivação do CAR apresenta-se como alternativa eficaz para evitar a expansão destas áreas e a possível recuperação das mesmas. EMBRAPA (2012) revela a perda anual do solo em Minas Gerais e incentiva à adoção dos processos de correção dos solos e de plantio de culturas, como o sorgo, que mantenham a cobertura podológica e, preenchimento das áreas de reposição florestal propostas nas medidas mitigadoras e compensatórias propostas no DAIA, com plantios de espécies nativas da mesma bacia da cobertura vegetal nativa retirada. O CAR com a política da inserção das áreas de vegetação remanescente e com a prescrição do Novo Código Florestal que prevê que propriedades em que não há vegetação disponível podem e devem disponibilizar uma área de solo exposto para plantio de espécies que venham a compor a reserva legal pode e muito auxiliar na redução destas áreas lacunosas do mapa do município de Montes Claros MG. 
Mapa da vegetação nativa declarada no Cadastro Ambiental Rural - CAR em Montes ClarosMG

Wagner Aparecido Silva

No tocante às áreas de cor branca no mapa, referentes à vegetação existente, mas não cadastrada no CAR, a pandemia da covid 19 não possibilitou a verificação do porquê este potencial fitológico não ter sido declarado, mas algumas associações dos produtores rurais com que se foi possível dialogar, antes da pandemia da covid 19, informaram que muitos produtores tiveram problemas com a emissão do cadastro, porque a lida com o sistema SICAR requer prática e conhecimento prévio, outros tiveram problemas com a documentação de posse das propriedades, uma vez que o CAR exige a matrícula, mas muitas propriedades no município de Montes Claros -MG são terras devolutas, cessão de direitos de herança, e , como o CAR exige a matrícula da certidão de registro do imóvel ou a matrícula da declaração de posse registrada em cartório de títulos e documentos, o sistema não deferiu o cadastro. Atribui-se ainda o quantitativo de vegetação não cadastrada a problemas dos produtores com o georreferenciamento da propriedade, porque se o memorial descritivo da área total, da área da reserva florestal legal e da área de preservação permanente apresentar quaisquer incorreções no sistema de coordenadas, o sistema SICAR não defere o cadastro. Na ponta do extremo oeste e no noroeste montesclarense, percebe-se intensa quantidade de vegetação não cadastrada, porque é uma área onde há predomínio de floresta plantada (eucalipto) e os dados fornecidos pelo IEF através do sistema SICAR só contemplam a vegetação nativa declarada. Predomina vegetação não cadastrada no CAR ainda na borda situada a sudeste que é referente às áreas de preservação permanente próximas à barragem de Juramento e nos topos de morro e terras altas que divisam Montes Claros -MG e Juramento, bem como Montes Claros, Guaraciama e Bocaiúva - MG. Isso pode ser explicado pelo fato de a vegetação das áreas de APPs ter sido cadastrada à parte no CAR. Destacam-se as áreas com vegetação nativa não cadastradas no CAR, também, aquelas situadas no extremo sudeste do mapa, pois são onde está localizado o maior trecho de mata ciliar do rio Verde Grande, importantíssimo curso d'água para o município de Montes Claros -MG e a vegetação ciliar da barragem de Juramento responsável pelo abastecimento hídrico da cidade. Há que verificar as razões da cobertura vegetal nativa destas áreas não terem sido declaradas e registradas no CAR, pois, segundo IGAM (2009), a maioria dos cursos d'água do nosso município são intermitentes, os índices pluviométricos aqui são baixos e a vegetação é um agente efetivo para melhor pluviosidade, recarga de aquíferos e até maior captação por parte da barragem e elevação de seus níveis hídricos. De acordo com SUDENE (2017), na questão ambiental, há um aumento nos centros urbanos, por vezes desordenados e baixos padrões de saneamento, tornando os ambientes menos saudáveis e contribuindo para a deterioração dos rios. Além disso, o desmatamento, o uso inadequado da terra, entre outras questões, juntamente com as mudanças climáticas, tem contribuído para o 
Mapa da vegetação nativa declarada no Cadastro Ambiental Rural - CAR em Montes ClarosMG

Wagner Aparecido Silva

avanço do processo de desertificação na região norte mineira. Atribui-se ainda as porções não cadastradas às áreas dos $20 \%$ da Reserva Legal dos imóveis e à vegetação presente nas APPs. O IEF informou nos dados disponibilizados por ocasião do projeto de construção deste artigo, em 2020, que o cadastro da cobertura vegetal nativa referente à RL e APP foi declarado e cadastrado à parte no CAR.

As áreas em cores verdes escuras no mapa, ainda que o quantitativo fornecido pelo SICAR não situe com precisão cada uma das propriedades por nomenclatura, mas o generalizado é que as áreas em vermelho são porções de vegetação cadastradas com áreas que vão de 01 a 69 hectares. Não se trata de uma única propriedade! Até por que estão distribuídas pelo mapa, em uns pontos com predominâncias e em outros com limitadas ocorrências. Pode-se inferir que as áreas em verde escuro predominam nas propriedades localizadas ao norte e nordeste do município de Montes Claros -MG, caracterizam a pequena propriedade, porque para Montes Claros, a Lei 12.651/2012 informa que o módulo fiscal totaliza 40 ha e a pequena propriedade é aquela enquadrada em até 04 módulos fiscais, isto é, 160 hectares. Na região sudeste de Montes Claros e na porção oeste, percebe-se que as cores verdes escuras não predominam. É preciso levar em conta que, conforme a base de dados fornecida pelo IEF através do SICAR, a vegetação cadastrada refere-se à vegetação nativa, excetuando: o percentual de $20 \%$ de reserva florestal legal, à vegetação remanescente e às áreas de preservação permanente. Assim sendo, ficam estas áreas em verde escuro caraterizadas como cobertura vegetal nativa das pequenas propriedades, seus percentuais de vegetação declarada baixos e se localizam em pontos indicadores de porções do espaço destinadas à lavoura, bovinocultura, formação de pastagem e silvicultura. Entretanto, embora aparentemente pequenas, são porções de vegetação importantes, pois se trata de propriedades de onde o agricultor tira seu sustento e para isso aconteceu supressão da cobertura vegetal nativa. De acordo com Pougy et al.,(2015, p.23) a expansão das florestas plantadas, da pecuária e agricultura, sem o devido cuidado para a conservação dos recursos naturais, tem gerado fortes pressões sobre o ambiente natural da região norte-mineira, colocando alguns animais e plantas em estado de ameaçados de extinção, e também causando o desaparecimento dos cursos de água, colocando a região na categoria de prioridade de recuperação média a muito alta. A vegetação cadastrada referente à pequena propriedade apresenta-se como instrumento de regularização ambiental eficiente no combate a estes desequilíbrios e certamente o CAR oferece oportunidade de monitoramento e do pequeno produtor rural utilizar o solo de forma sustentável. 
Mapa da vegetação nativa declarada no Cadastro Ambiental Rural - CAR em Montes ClarosMG

Wagner Aparecido Silva

Em análise às áreas em verde claro no mapa coroplético, referentes à vegetação declarada em porções de cerca de 70 a 300 hectares, interpreta-se que este percentual significativo de vegetação sobretudo na porção central do município de Montes Claros, nos imóveis localizados entre a cidade de Montes Claros, o distrito de Miralta e Nova Esperança. A norte, estes quantitativos de vegetação cadastrada no CAR também são destaques. A razão das áreas em verde claro se destacarem nestas regiões evidencia que são propriedades até e acima de 04 módulos fiscais. A Lei 12.651/2012, ou novo código florestal, diz que, quando a propriedade ultrapassa os 04 módulos fiscais, está sujeita à elaboração de planta topográfica com o devido georreferenciamento e quantitativo exato em hectares da vegetação disponível na reserva legal e APP e respectivo cadastro da planta no CAR. As áreas em verde claro, como estão distribuídas em imóveis onde ocorreram supressão de vegetação nativa para fins de pastagem, plantio, pivô central e bovinocultura são importantes, porque se referem a vegetação de Cerrado Stricto Sensu o que evidencia que Montes Claros tem uma significativa média de vegetação de cerrado a monitorar e preservar nestas propriedades que fizeram o uso regular do solo, mas preservaram a Reserva Legal, as áreas de APPs e vegetação remanescente.

Os polígonos em amarelo e alaranjado apresentam vastos hectares de vegetação nativa cadastrados no CAR: amarelos se referindo às porções de vegetação com cerca de 300 a 936 hectares de cobertura vegetal nativa declarada e os polígonos alaranjados: 937 a 2.906 hectares. É notável que, embora sejam um percentual relevante de vegetação cadastrada, mas no mapa não são majoritárias, exatamente porque se referem a conjuntos de vegetação de grandes propriedades. Segundo a Lei 12.651/2012, a média e grande propriedade são aquelas cujas áreas entre 4 a 15 módulos fiscais. O mapa mostra que são propriedades com quantidade considerável de vegetação declarada localizadas ao sul de Montes Claros -MG nas proximidades com o distrito de Canto do Engenho, na porção sudeste, norte e noroeste do Parque Estadual da Lapa Grande a oeste da cidade de Montes Claros -MG. A considerável quantidade de vegetação declarada e preservada nestas áreas pode estar relacionada certamente às resoluções do CONAMA (2002) acerca de cobertura de vegetação nativa existente em imóveis localizados no entorno das unidades de conservação. Ademais, empresas com vastas propriedades rurais como a PLANTAR S/A, a Lafarge e a RIMA Industrial evidentemente cadastraram significativa quantidade de cobertura vegetal nativa, tanto de Reserva Legal, quanto de vegetação nativa e o potencial de Cerrado e Mata Seca nas referidas propriedades, porque as medidas mitigadoras e compensatórias do DAIA e da Licença Ambiental assim o exigem. 
Mapa da vegetação nativa declarada no Cadastro Ambiental Rural - CAR em Montes ClarosMG

Wagner Aparecido Silva

A grande área vermelha, que segundo o quantitativo disponibilizado pelo IEF/ SICAR se referem a um total de cerca de 2.907 a 7.773 hectares de vegetação declarada no CAR é o destaque do mapa coroplético. Representa a vegetação das propriedades localizadas no entorno ou dentro da unidade de conservação - Parque Estadual da Lapa Grande, a oeste da cidade de Montes Claros -MG. Como se pode ver, refere-se a um potencial significativo de cobertura vegetal nativa de Cerrado e Floresta Estacional Decidual (Mata Seca) que foram declaradas e registradas no CAR e abrigam grande biodiversidade vegetal e espécies da fauna montesclarense. O destaque e amplidão da área vermelha em relação às demais cores do mapa explicam-se pelas políticas públicas ambientais que vêm sendo adotadas desde a criação desta unidade de conservação e aplicação das legislações ambientais que prescrevem a defesa da biodiversidade caraterística destas áreas. Têm sido destacado que o Cerrado e a Mata Atlântica são, provavelmente, os ecossistemas mais devastados e mais ameaçados do planeta, conforme SCOLFlORO, J. R.; CARVALHO, L. M. T.,(2006, p.42). Assim sendo, estes hotspots enquadram-se hoje na categoria de muito alta a média de prioridade para conservação no geral, principalmente para flora e alguns grupos de fauna. A criação das UCs atende às necessidades ambientais sustentáveis destes biomas e suas respectivas faunas. E em Montes Claros -MG, o CAR para a vegetação no entorno e dentro do Parque Estadual da Lapa Grande representa maior monitoramento, pois intervenções como as que aconteceram em 2010 na Serra do Sapucaia e a atividade mineralógica no Morro Dois Irmãos e outras formas de supressão da cobertura vegetal nativa representam impacto para a vegetação das UCs.

O mapa coroplético possibilitou ainda inferir que: quando se leva em conta o anexo à Lei 12.651/12, que informa que: 1 (um) módulo fiscal ${ }^{2}$ para o município de Montes Claros- MG equivale a 40 hectares, total este que o INCRA (2005) classifica: como minifúndio, ao imóvel rural com área inferior a 1 módulo fiscal; Como pequena propriedade, o imóvel de área compreendida entre 1 a 4 módulos fiscais; Como média propriedade, ao imóvel rural de área superior a 4 e até 15 módulos fiscais; Como grande propriedade, aquela de área superior a 15 módulos fiscais; percebe-se que a cobertura vegetal nativa da pequena propriedade constituída de 1 a 160 hectares, no mapa coroplético não é majoritária, mas as médias e grandes propriedades se destacam. A cobertura vegetal nativa cadastrada é um ganho para a

\footnotetext{
${ }^{2}$ Não é o mesmo que módulo rural que é uma unidade estabelecida por imóvel rural, onde cada um tem a sua dimensão em hectares, com base em quatro fatores básicos: forma, dimensão, localização no município e o aproveitamento econômico. Módulo fiscal é uma unidade fixada pelo INCRA, também em hectares, mas em que há uma mediana em um sistema de área única para o município. (INCRA, 2005, Instrução Especial núm.:03/2005)
} 
Mapa da vegetação nativa declarada no Cadastro Ambiental Rural - CAR em Montes ClarosMG

Wagner Aparecido Silva

biodiversidade e as políticas sustentáveis, tanto na pequena quanto nas médias e grandes propriedades, sobretudo nestas últimas, visto que nas médias e grandes propriedades é que, em Montes Claros -MG, há mais índices de supressão de vegetação para fins de bovinocultura e formação de pastagens, que, com licenciamento ambiental ou não, sempre redundam em perda para a biodiversidade, porque espécies vegetais nativas são suprimidas e espécies endêmicas daquela determinada fauna perdem seus respectivos habitats. A declaração e cadastro destes quantitativos de vegetação no CAR também são importantes, porque se referem a espécies vegetais nativas da bacia hidrográfica do município de Montes Claros, cuja forma de relevo predominante é a depressão sertaneja do São Francisco, com baixos índices pluviométricos, rios intermitentes e praticamente com seu percentual de espécies nativa de Mata Atlântica reduzidas, segundo INPE (2014) e, diante do fato que o Código Florestal de 1965 e o novo código prescrevem que a reposição florestal deve contemplar espécies nativas da mesma bacia e adaptáveis às condições pedológicas e climáticas, mas na prática isso não se concretiza sempre nas áreas desmatadas, o cadastro no CAR agrega valor ambiental para as espécies declaradas.

O programa de regularização proposto no CAR para Cerrado, Mata Seca montesclarenses que representam os biomas de maior proporção no norte de Minas Gerais, apresenta-se como estratégia que visa evitar impactos ambientais, levando em consideração toda a sua complexidade e sua interdependência com os biomas vizinhos. E, para que essas ações resultem em impactos positivos significativos para a conservação da biodiversidade nestes hotspots, é necessário direcionar todos os investimentos do poder público de maneira estratégica, priorizando o percentual, territórios declarados e cadastrados no CAR e procurar inquirir acerca destas áreas de vegetação que o mapa apresenta ausentes do cadastro, bem como fazer com que aquilo foi declarado, dentre as áreas do Cerrado e Mata Seca delimitados no mapa sejam áreas prioritárias a serem geridas e monitoradas pelos produtores rurais e pelo poder público.

O CAR, em Montes Claros -MG, traz uma esperança de tornar a seguridade ambiental efetiva, não só para as reservas legais, mas também nas áreas de preservação permanentes e os remanescentes de vegetação nativa, nas áreas de uso restrito e nas áreas consolidadas de uso do solo. O advento para essa seguridade ambiental, com todos os trâmites de regulamentação, se assegura com o Programa de Regularização Ambiental -PRA, estabelecido pelo Art. 59 da Lei 12.652/12 e pelo Decreto 7.830/12. Este programa estabelece um conjunto de ações ou iniciativas a serem envolvidas por proprietários e posseiros rurais com o objetivo de adequar e promover a regularização ambiental. O PRA é constituído de quatro instrumentos: o CAR, o termo de compromisso, o projeto de recuperação de áreas degradadas e as cotas de reservas legais, quando couber, sendo o CAR a chave para monitoramento e sucesso da regulamentação 
Mapa da vegetação nativa declarada no Cadastro Ambiental Rural - CAR em Montes ClarosMG

Wagner Aparecido Silva

ambiental, visto que é por meio dele que estarão disponíveis todas as informações integradas da propriedade com subsídios de mapas e fotos de satélites.

O mapa coroplético tema deste artigo contempla apenas o potencial de vegetação que foi declarado e cadastrado no CAR no município de Montes Claros -MG entre os anos de 2012 a 2019, mas o período estipulado para a União, os estados,órgãos estaduais, para os produtores rurais se enquadrarem no PRA foi estendido até 31 de dezembro de 2020. A Lei 13.295/16 tinha estipulado 31 de dezembro de 2017 como prazo final para inscrição no CAR, entretanto, a Lei 13.887/19 extinguiu o prazo de inscrição, mas o governo federal emitiu medida, colocando 31 de dezembro de 2020 como prazo final para os cadastrados se beneficiarem com as medidas envolvidas no PRA. Segundo Camargo (2013, p. 5), o prazo de cadastro não é suficiente para que se cumpram todas as etapas de implantação e execução desse novo modelo de gestão ambiental. Pertinente à observação desta autora, diante da complexidade do processo de regulamentação e adaptação ao novo sistema, que abrange a necessidade de vários estudos técnico/científicos e levantamento de todas as propriedades rurais abre precedente para argumentar que este mapa coroplético não é um mapa pronto, mas pode ser redesenhado e reconfigurado, a depender dos próximos quantitativos de vegetação declarados dentro da prorrogação do prazo e depois dela. Mas atinge seu objetivo de do ponto de vista da cartografia social concretizar-se como ferramenta de localização, quantificação e mapeamento posto para a população e o poder público: apreciarem e desenvolverem políticas no sentido de inquirirem a motivação pela qual grande potencial de vegetação não foi cadastrada e declarada sobretudo em áreas vitais para a biodiversidade montesclarense, monitorar o que foi declarado e preservar o que se tem.

\section{CONSIDERAÇÕES FINAIS}

O CAR surge como uma ferramenta eficaz de regularização ambiental e conservação da biodiversidade, porque não só possibilita o cadastro da propriedade e suas respectivas: áreas de reserva legal, de preservação permanentes, de uso consolidado e vegetação remanescente, mas o monitoramento e fiscalização destas. O mapa coroplético da cobertura vegetal nativa domunicípio de Montes Claros-MG, elaborado a partir daquilo que a base de dados disponibilizados pelo órgão ambiental estadual competente forneceu é um mapeamento importante na condução de estudos para conservação da biodiversidade, pois ao mapear e quantificar estas áreas, não só mostra a necessidade de conservá-las, mas também de inserir a vegetação não cadastrada e conduzir o observador à localização das áreas de ocupação antrópica. O mapa alcança seu objetivo de localizar, quantificar e colorir, mas convida também 
Mapa da vegetação nativa declarada no Cadastro Ambiental Rural - CAR em Montes ClarosMG

Wagner Aparecido Silva

à mobilização de políticas e programas ambientais que se atentem às porções coropléticas dele que mostram a biodiversidade vegetal em desvantagem em relação às áreas de uso antrópico.

\section{REFERÊNCIAS}

ACSELRAD, Henri (Org.). Cartografia Social e Dinâmicas Territoriais: marcos para o debate. Rio de Janeiro: Universidade Federal do Rio de Janeiro, Instituto de Pesquisa e Planejamento Urbano e Regional, 2010.

ANDRADE, Manuel Correia de. A questão do território no Brasil. São Paulo: Editora Hucitec, 2004.

BRASIL. Ministério do Meio Ambiente. Decreto no 7.830, de 17 de outubro de 2012. Instituiu o Sistema de Cadastro Ambiental Rural - CAR, estabelece normas de caráter geral aos Programas de Regularização Ambiental. Brasília: DOU de 18/10/2012b.

BRASIL. Ministério de Meio Ambiente. Lei no 11.428 de 22 de dezembro de 2006. Dispõe sobre a vegetação nativa do Bioma Mata Atlântica e dá outras providências. Disponível em: <http://www.planalto.gov.br/ccivil_03/_ato2004-2006/2006/lei/111428.htm020>. Acesso em 23 mai. 2020.

BRASIL. Ministério do Meio Ambiente. Lei n. 12.651, de 25 de maio de 2012. Dispõe sobre a proteção da vegetação nativa e o Cadastro Ambiental Rural - CAR; altera as revoga as Leis núm.: 4.771, de 15 de setembro de 1965, e 7.754, de 14 de abril de 1989.Disponível em: http://portal.in.gov.br/>. DOU de 28/05/2012. Acesso em 23 de maio de 2020.

BRASIL. Ministério do Meio Ambiente. Lei n. 13.887, de 17 de outubro de 2019. Art. $7^{\text {o }}$ : Caso os Estados e o Distrito Federal não implantem o PRA até 31 de dezembro de 2020, o proprietário ou possuidor de imóvel rural poderá aderir ao PRA implantado pela União. Disponívelem:<http://www.planalto.gov.br/ccivil_03/_ato2019-2022/2019/lei/L13887.htm>. Acesso em 23 de maio de 2020.

BERTRAND, Georges. Paisagem e Geografia Global: esboço metodológico. São Paulo, Instituto de Geografia da USP, 1972.

Cadastro Ambiental Rural começa a funcionar este mês. O Globo, 2014. Disponível em: <http://www.imirante.globo.com>. Acesso em 19 de agosto de 2020.

CAMARGO, Flávia. Os rumos do Cadastro Ambiental Rural (CAR) precisam mudar. 2013. Instituto Sócioambiental - ISA. Disponível em: <www.socioambiental.org>. Acesso em 26 de outubro de 2020.

CONSELHO NACIONAL DO MEIO AMBIENTE (CONAMA). Resolução n. ${ }^{\mathbf{0}} \mathbf{3 0 3}$, de 28 de março de 2002. Dispõe acerca das áreas de preservação permanente e vegetação no entorno das Unidades de Conservação. Brasília: DOU de 13/05/2002. 
Mapa da vegetação nativa declarada no Cadastro Ambiental Rural - CAR em Montes ClarosMG

Wagner Aparecido Silva

EMPRESA BRASILEIRA DE PESQUISA E AGROPECUÁRIA (EMBRAPA). Estimativas da perda anual do solo em Minas Gerais. 17 de julho de 2011. Disponível em:<https://www.embrapa.br/estimativa-da-perda-anual-dos-solos-em-minas-gerais/> Acesso em 21 de janeiro de 2021.

FITZ, Paulo Roberto. Geoprocessamento sem complicação. São Paulo: Oficina de Textos, 2008. 160 p.

FUNDAÇÃO SOS MATA ATLÂNTICA. Minas lidera novamente o rancking de desmates. 25 de maio de 2016. Disponível em: < https://www.sosma.org.br/noticias/mg-volta-liderarranking-de-desmatamento $>$. Acesso em 21 de janeiro de 2021.

HAESBAERT, Rogério. O mito da desterritorialização: do "fim dos territórios" à multiterritorialidade. Rio de Janeiro: Bertrand Brasil. 2004.

INSTITUTO BRASILEIRO DE GEOGRAFIA E ESTATÍSTICA (IBGE). Resultados preliminares do Censo Agropecuário confirmam expansão da fronteira agrícola. 2006. Disponível em:<http://saladeimprensa.ibge.gov.br>. Acesso em 13 de novembro de 2020.

INSTITUTO ESTADUAL DE FLORESTAS (IEF). O Cadastro Ambiental Rural CAR.Disponível em <http://www.ief.mg.gov.br/cadastro-ambiental-rural-car> Acessado em 27 de setembro de 2020 .

INSTITUTO MINEIRO DE GESTÃO DAS ÁGUAS (IGAM). Plano diretor de recursos hídricos da Bacia Hidrográfica do Rio Verde Grande/Instituto Mineiro de Gestão das Águas, Comitê da Sub-Bacia Hidrográfica do Rio Verde Grande. Belo Horizonte, 2009.Disponível em:< http://portalinfohidro.igam.mg.gov.br/planos-diretores>. Acesso em 23 de novembro de 2020.

INSTITUTO NACIONAL DE COLONIZAÇÃO E REFORMA AGRÁRIA - INCRA Instrução Especial/ Incra/ $\mathbf{n}^{\circ}$ 03, de 11 de abril de 2005. Estabelece o Módulo Fiscal para os Municípios constantes da tabela anexa. Diário Oficial [da] República Federativa do Brasil,Brasília,DF,12abr.2005.Seção1.Disponívelem: <http://www.jusbrasil.com.br/diarios/32 1585/dou-secao-3-12-04-2005-pg-110>. Acesso em:26 de novembro de 2020.

INSTITUTO ESTADUAL DE PESQUISAS ESPACIAIS (INPE). Banco de Dados Geomorfométricos do Brasil. Brasília,2014. Disponível:<http://www.dsr.inpe.br/topodata/> Acessado em 27 de setembro de 2020.

INSTITUTO NACIONAL DE METEREOLOGIA (INMET). Precipitação total anual e gráficos climáticos. Brasília, 2017. Disponível em: < http://www.inmet.gov.br/portal/> . Acesso em 16 de agosto de 2020.

MINAS GERAIS. Secretaria do Estado do Meio Ambiente e Desenvolvimento Sustentável. Lei Estadual 20.922, de 16 de outubro de 2013: regulamenta Novo CódigoFlorestal.Disponívelem: $<$ https://www.almg.gov.br/consulte/legislacao/completa/com pleta-nova min.html?tipo=Lei\&num=20922\&ano=2013> . Acesso em 26 de maio de 2020. 
Mapa da vegetação nativa declarada no Cadastro Ambiental Rural - CAR em Montes ClarosMG

Wagner Aparecido Silva

MINISTÉRIO DO MEIO AMBIENTE (MMA). Propriedades rurais terão cadastro ambiental. 2013. Disponível em: <http://www.brasil.gov.br/>. Acesso em março de 2013.

POUGY, N.; VERDI, M.; MARTINS, E.; MAURENZA, D.; LOYOLA, R.; MARTINELLI, G. (Orgs.). Plano de ação nacional para a conservação da flora ameaçada de extinção da região de Grão Mogol-Francisco Sá. Rio de Janeiro. CNCFlora: Jardim Botânico do Rio de Janeiro: Laboratório de Biogeografia da Conservação: Andrea Jakobsson Estúdio, 2015. 76 p.

SCOLFORO, J. R.; CARVALHO, L. M. T. (Ed.). Mapeamento e Inventário da Flora e dos Reflorestamentos de Minas Gerais. Lavras: UFLA, 2006. Disponível em:<http://paufurado.blogspot.com/p/inventario-florestal-de-minas-gerais.html.>. Acessado em 21 de janeiro de 2021.

SISTEMA INTEGRADO DE MONITORIA (SIM -SISIEF). Relatório de emissão de Documento Autorizativo de Intervenção Ambiental - DAIA: de 2009 a 2015. Disponibilizado pelo Núcleo de Regularização Ambiental de Montes Claros - IEF - Escritório Regional Norte, em 27 de junho de 2016.

SISTEMA NACIONAL DE CADASTRO AMBIENTAL RURAL - SICAR. Boletim informativo da quantidade de biomas cadastrados no CAR. Disponível em: <https://www.florestal.gov.br/images/conteudo/car/boletim_informativo/infografico>. Acesso em 26 de maio de 2020.

SLOCUM, T. A.; MCMASTER, R. B.; KESSLER, F. C.; HOWARD, H. H. Cartografia Temática e Geovisualização. 3rd ed. EUA: Prentice Hall Series in Geographic Information Science, 2009. Trad.: Editora Amazon.com.

SOTCHAVA, V.B. O estudo de geossistemas. São Paulo, Instituto de Geografia da USP, 1977. P.51 (Métodos em Questão).

SUPERINTENDÊNCIA DO DESENVOLVIMENTO DO NORDESTE - SUDENE. Plano estratégico de desenvolvimento do norte e nordeste de Minas Gerais. Brasília, 2017. Disponível em:〈http://sudene.gov.br/planejamento-regional/planos-de desenvolvimento>. Acessado em 21 de janeiro de 2021.

Artigo recebido em: 14 fevereiro de 2021

Artigo aceito em: 29 de março de 2021.

Artigo publicado em: 05 de abril de 2021. 